and yet Professor Henker states that a-13D of actual myopia (corrigible by a-15.73D placed at $12 \mathrm{~mm}$. from the cornea) "would become exactly normal-sighted by the surgical removal of the lens." Does not Professor Henker know that the retinal images of a corrected aphakic are more than a third larger than those of a "normal-sighted" person?

The constants used are grossly erroneous and must have been taken from a very abnormal eye, and hence the tables calculated from them are misleading.

A great part of this book is devoted to extolling the punctal and katral lenses, but no indication is given of the method of calculating their surfaces.

The characteristics of a scientific book are truth and logical reasoning from accepted premises. In both these characteristics this book fails. If it had attempted to fulfil the second requisite only, one would have pointed out where the error lay to the author, for there is a very close tie of brotherhood binding all scientific workers together. This book, however, is little more than an advertisement of certain lenses, the real structure of which is secret.

\title{
CORRESPONDENCE
}

\section{MEDICAL TREATMENT OF CATARACT}

\section{To the Editor of The British Journal of Ophthalmology}

SIR,-We read of medical treatment of cataract, and of improved vision after years, mostly slight. Most of us, I suppose, have tried some of it, and some of us, bravely, have tried to make the most of the "improvements." Are these improvements in vision reliable evidence of effective treatment? I doubt it very much indeed. Without being able to put before you specimens, and without claiming proof for these remarks on ground of special research, I write merely as a clinician and practitioner who has taken notes. Have we not all recorded cases of senile cataract, where the patient comes at intervals of six months, a year or more, to find out whether the cataract is maturing, and where we. find the acuity of vision at a later visit better than at a former one? I take it to be a foregone conclusion that in the development of senile cataract there is a steady battle waging between breakdown of tissue on the one hand and the powers of repair on the other. The decision whether progress, or otherwise, of the cataract will result, depends upon which gains the upper hand. New vacuoles and striae form, and quite certainly others are 
cleared away. Restitutio ad integrum in the smallest patch involved in the path of light rays will naturally produce better acuity. The "sometimes I see better than other times" of our patients is not always attributable to illumination and the action of the pupil. Then there is the fact that even normal eyes have better visual acuity on some days than on others. I can see my $6 / 3$ some days when working on my patients; on others even $6 / 6$ is uncertain. So many factors are here at play, that most records, where improvements are slight, must be taken cum grano salis.

While I have failed to note any improvement from medical treatment in my own cases and those of others, I have had at least half a dozen cases of spontaneous absorption of cataract, and would have to deny the evidence of my own eyes were I to question that absorption and degeneration march along hand in hand. At present I will only quote here four cases; the remainder are swamped somewhere in my card cabinet.

Case 1. An aunt of mine, Mrs. W.A.S. of Ealing, with M. ca. 10D, had, when I left England in 1904, a perfectly clear lens in her only eye-the other was removed by von Graefe many years ago. I was absent till 1914. During my absence Mr. A. Bruce Roxburgh saw her repeatedly and noted striae in the lens. On my return in 1914 she was much concerned about her "cataract," but her vision was excellent, and the lens was perfectly clear, without a vestige of a stria or a vacuole. It is redundant to add that the observation of striae during my absence is quite incontestable. A couple of years ago a new opacity appeared where it so frequently first sets in-down and inwards. Whether this will again undergo resorption at her advanced age of over 80 remains to be seen.

Case 2. Mrs. John B., aged 60, I experienced in New York. In July, 1909, she noticed that her sight was getting hazy. The right lens showed vacuoles throughout, $V:=20 / 70$ correcting to $20 / 50$. The left lens showed two sectors of vacuoles, up and in, and down and out, almost meeting with their apices at the centre of the lens. $\quad \mathrm{V} .=20 / 40$ correcting to $20 / 20 \mathrm{pt}$. The patient being of a very worrying disposition, I only informed several of her relatives, who kept my counsel faithfully. On May 1, 1912, $\mathrm{R} . \mathrm{V}$. = fingers at 0.5 metre, correcting, with compound minus lenses, to $20 / 70$. L.V $:=15 / 15$ pt. correcting to $15 / 15$, and to my astonishment (it being the first occasion on which I had observed this), all lenticular opacities had disappeared in the left eye. I had made careful drawings of both lenses in July, 1909.

Case 3. Rev. T.St.R., Lexden, consulted me here on August 23,1916 , because he noticed a blur on print which annoyed him considerably in the pulpit. The right eye showed incipient cataract, quite a large blotch of it, in the common situation, down 
and in. Also some opacity in, or near, the posterior capsule, and some annoying vitreous opacities. R.V.=18/20; L.V.$=18 / 15$, and the lens was quite clear. I was at the time trying 5 per cent. sodium iodide eyedrops, twice daily for periods of five weeks at a time, with sat. sol. Pot. Iod. internally. I found them well tolerated, but had no success. This patient insisted on knowing his condition and I was obliged to tell him, contrary to my custom. I suggested and urged him to try these eyedrops and prescribed them, as well as Pot. Iod. Fortunately, he used neither one nor the other! Because, had he done so, I would have been tempted to ascribe the fact that on July 23,1917 , he had no more trace of opacity in the right lens, and that his vision had improved to $18 / 15$, to the use of the medicine. I saw him again in July, 1921 . Both lenses were clear (capsular opacity and vitreous opacities likewise), and V.=18/15 in each eye. Probably the posterior opacity was not strictly speaking in the capsule, but in the cortex immediately adjoining it.

Case 4. Though this may appear "dragged in by the hair," it is yet one of absorption of lens opacities. Mr. F.S.W., aged 58, I saw often in New York from July, 1910 to October, 1912. He was a patient of Professor Dr. C. van Norden, Vienna, and had had for years diabetes mellitus, but through careful observance of his régime, was well and active. He used to get occasional attacks of amblyopia, during which he could not read at all. I saw him in a couple of these, and both lenses were soapy and the fundus could not be seen. The condition always cleared up completely in the course of a few days, and all was well again. A glutinous conjunctival secretion sometimes accompanied these attacks. The case is remarkably interesting, and I reported it to Professor van Norden at the time, who had heard of other such cases.

I examine the lens with the Marple electric ophthalmoscope and $a+16$ in the aperture-a very severe test indeed. I doubt if it can be beaten, unless possibly by the slit-lamp. But a lens that will pass this test and show the fundus clearly also, is to all clinical intents and for purposes of function, perfect, whatever the slit-lamp may yet reveal.

COLCHester,

August 2, 1924.

Yours faithfully,

George Young.

\section{NOTES}

Mr. A. F. MacCallan, C.B.E., has been

Appointments appointed Consulting Ophthalmic Surgeon to the Cassel Hospital for Functional and

Nervous Disorders. 